\title{
Dependence Properties of Sol-Gel Derived CuO@SiO Nanostructure to Diverse Concentrations of Copper Oxide
}

\author{
V. Homaunmir, ${ }^{1}$ S. H. Tohidi, ${ }^{1}$ G. Grigorya, ${ }^{2}$ and M. Ayatollah Zada Shirazi ${ }^{3}$ \\ ${ }^{1}$ Agricultural, Medical, Industrial Research School, NSTI, P.O. Box 31485- 498, Karaj, Iran \\ ${ }^{2}$ Yerevan State University, 1 Alex Manoukian Street, 375049 Yerevan, Armenia \\ ${ }^{3}$ Islamic Azad University, Lahijan Branch, Guilan, Iran
}

Correspondence should be addressed to S. H. Tohidi; htouhidi@yahoo.com

Received 21 May 2013; Revised 18 August 2013; Accepted 21 August 2013

Academic Editor: Xiangwu Zhang

Copyright (C) 2013 V. Homaunmir et al. This is an open access article distributed under the Creative Commons Attribution License, which permits unrestricted use, distribution, and reproduction in any medium, provided the original work is properly cited.

\begin{abstract}
Various concentrations of copper oxide were embedded into silica matrix of xerogel forms using copper source $\mathrm{Cu}\left(\mathrm{NO}_{3}\right)_{2} \cdot 3 \mathrm{H}_{2} \mathrm{O}$. The xerogel samples were prepared by hydrolysis and condensation of tetraethyl orthosilicate (TEOS) with determination of new molar ratios of the components by the sol-gel method. In this paper, three samples of copper oxide were doped into silica matrices using different concentrations. We obtained 10, 20, and $30 \mathrm{wt} \%$ of copper oxide in silica matrices labeled as A, B, and $\mathrm{C}$, respectively. The absorption and transmittance spectra of the gel matrices were treated at different concentrations by Uv-vis spectrophotometer. Quantities of water and transparency in the silica network change the spectral characteristics of $\mathrm{Cu}^{2+}$ ions in the host silica. Absorption spectra of the samples heated to higher concentration complete the conversion of $\mathrm{Cu}^{2+}$ ions to $\mathrm{Cu}^{+}$ ions. The effects of concentration of copper oxide were characterized by X-ray diffraction (XRD) patterns, and the transmission electron microscope (TEM) micrographs. Also, textural properties of samples were studied by surface area analysis (BET method) at different concentrations.
\end{abstract}

\section{Introduction}

Sol-gel processing is a relatively new technique in the preparation of glasses and primarily to get potentially high purity and homogeneity as well as low processing temperatures compared with the traditional glass melting techniques [1]. Hydrolysis and polycondensation of alkoxide precursors followed by aging and drying are of the best methods used for making sol-gel of silica monolith [2]. The monoliths processed by sol-gel method allowed metal ions and rare earth ions to incorporate transition metal in their matrices. Introducing transition metals into hydrolysable precursors through sol-gel method permits the formation of numerous novel materials that exhibit important optical and/or catalytic properties [3,4]. Copper or copper oxides in oxide matrixes have attracted sustained interest due to their unusual properties [5]. Mohanan and Brock [6] have studied copper oxide silica aerogel composites by varying $\mathrm{pH}$ values, copper precursor salts, and treatment temperatures. They found that based-catalyzed gels underwent a gradual change from bonded $\mathrm{Cu}^{+2}$ ions to segregated copper oxide at different heating conditions. Parler et al. [7] observed silicon-oxygenmetal bond formation during both the synthesis and drying stages at low temperatures. Host matrices embedded with copper have been produced to study their properties as tunable visible light solid-state lasers and colored coatings $[8,9]$. The mechanical properties of $\mathrm{Cu}$-doped silica gels in the form of xerogels, coatings, and powders have been studied extensively [10]. The structural evolutions of copperdoped porous silica gels treated at different temperatures have also been studied [11, 12]. So far no reports have been seen on different concentrations effect of copper oxide on the optical, structural, and textural properties of $\mathrm{CuO} @ \mathrm{SiO}_{2}$ nanostructures. The aim of present work is understanding the effect of concentration on the spectroscopic properties of different copper concentrations (10,20, and 30 wt.\%). 


\section{Experimental Procedure}

2.1. Sample Preparation. In this work, the raw materials consisting of tetraethyl orthosilicate (TEOS) (Fluka, 98\%), ethanol absolute (EtOH) (Merck), and copper nitrate trihydrate $\left(\mathrm{Cu}\left(\mathrm{NO}_{3}\right)_{2} \cdot 3 \mathrm{H}_{2} \mathrm{O}\right)$ (Merck), as initial solution, and nitric acid $\left(\mathrm{HNO}_{3}\right)(\mathrm{Merck}, 65 \%)$ and acetic acid $\left(\mathrm{CH}_{3} \mathrm{COOH}\right)$ (Merck, 99-100\%), as catalysts, were used. Three samples of $\mathrm{CuO} @ \mathrm{SiO}_{2}$ nanocomposite in xerogel form were prepared by the sol-gel method, and the fourth sample was prepared as a blank using TEOS hydrolyzed with $\mathrm{HNO}_{3}$, $\mathrm{CH}_{3} \mathrm{COOH}$, EtOH and deionized (DI) water in the new total molar ratio of TEOS : ETOH : $\mathrm{H}_{2} \mathrm{O}=1: 1.3: 6.2$ [12].

The appropriate amounts of trihydrated copper nitrate were added to the solution, so that the concentrations of copper oxide in the final products reached 10, 20, and $30 \mathrm{wt} . \%$ (labeled as A, B, and C, resp.). Then the solutions were mixed by magnetic stirrer for 1.5 hours to make them more homogeneous. The solution acidity $(\mathrm{pH})$ was measured by $\mathrm{pH}$ meter as 2.4. The samples were kept in a close container at $25-30^{\circ} \mathrm{C}$. The soft gel was prepared till a dark-blue color appeared within 84 hours via gelatin treatment. Then the gel samples were dried in an oven at $80-110^{\circ} \mathrm{C}$ in air for 1 hour to complete the gelatin process [13]. The gel samples were then annealed at the temperature range of $100-1000^{\circ} \mathrm{C}$ with rate of $50^{\circ} \mathrm{C} / \mathrm{h}$ for 2 hours, using electric furnace to form the condense nanocomposites [14-16]. The blank solution was prepared using the above-mentioned procedure but with no $\mathrm{Cu}\left(\mathrm{NO}_{3}\right)_{2} 3 \mathrm{H}_{2} \mathrm{O}$ application.

2.2. Characterization. Characterizations of ultraviolet-visible (Uv-vis) spectra of samples were prepared under experimental conditions by Uv spectrophotometer, model BEKMAN (DU-600).

The X-ray diffraction (XRD) patterns were prepared by a Philips instrument using PW1800 diffract meter and radiation of copper anodic tube $\lambda=1.54 \AA$.

A transmission electron microscope (TEM), Em208S series (Philips Company), operating at $100 \mathrm{kV}$ was used in this work. The dry samples were ground, suspended in dry cyclohexane, and sonicated for 30 minutes. Then the solutions were allowed to settle, and a droplet of the resulting supernatants was placed on a holey carbon film and dried.

The porosities of the samples were analyzed by nitrogen adsorption/desorption measurements fitted to a BET isotherm using an Autosorb instrument (Quanta-chrome, Nova 1200). The samples were pretreated for $3 \mathrm{hrs}$ under vacuum at $100^{\circ} \mathrm{C}$ (for the sample dried at $100^{\circ} \mathrm{C}$ ) and at $200^{\circ} \mathrm{C}$ (for samples treated at 400,800 , and $1000^{\circ} \mathrm{C}$ ). Gaseous nitrogen was used with a 5 -hour adsorption/desorption cycle.

The condensation and annealing of the samples were performed in a heat furnace with high thermal capacity $\left(1500^{\circ} \mathrm{C}\right)$.

\section{Results and Discussion}

3.1. Spectroscopy Characteristics. Figure 1 exhibits the absorption spectra of the samples A, B, and C heated at $200^{\circ} \mathrm{C}$. As shown, all of the doped gel samples present an absorption

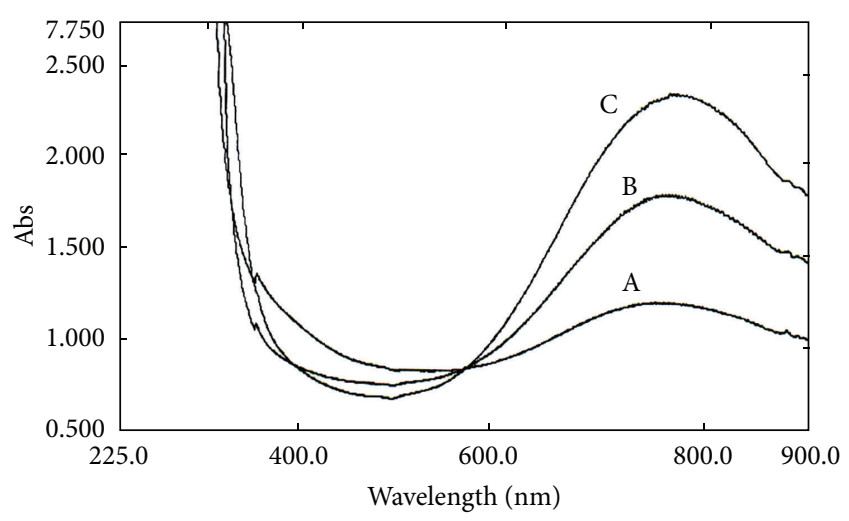

Figure 1: Absorption spectra of the samples A, B, and C heated at $200^{\circ} \mathrm{C}$.

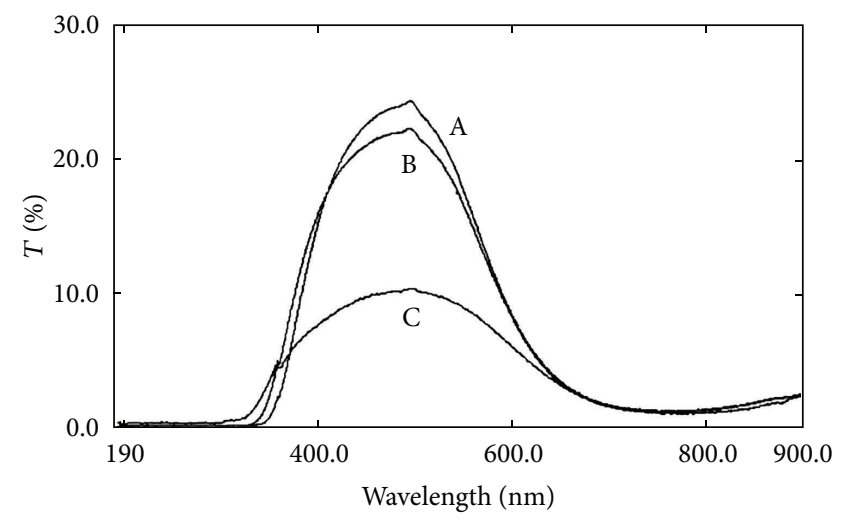

Figure 2: The transmittance spectra of the samples A, B, and C.

band around the $780 \mathrm{~nm}$ wavelength, which explains the presence of $\mathrm{Cu}^{+2}$ ions in the gel matrix. This absorption intensity increases for higher concentrations of copper ions in volume unit. This figure presents with increasing of concentration copper oxide, the intensity of peaks increases and amounts $\mathrm{Cu}^{2+}$ raises in volume unit. Also, the incorporation of copper ions in the matrix up to $700^{\circ} \mathrm{C}$ was confirmed by the absorption spectra [16].

It is known that impurity of water in oxides appearing in the form of hydroxyl groups produces absorption band in the NIR region. Sometimes it has been observed that an absorption band in the violet region ( $400 \mathrm{~nm}$ ) exhibits copper oxide colloidal particles in the matrix. But it is surprising that no absorption band has been seen in this range due to low concentration of the copper ions and low acidity of the samples. Figure 2 presents the transmittance spectra of the samples $\mathrm{A}, \mathrm{B}$, and $\mathrm{C}$ at different concentrations. The dark-blue color of gel samples is related to the transmittance spectrum indicating maximum transmittance in the $400-$ $600 \mathrm{~nm}$ range.

Because of high purity and low volume of water, these samples show high transmittance. These observations indicate that the samples have filtering effect in the $400-600 \mathrm{~nm}$ range. 


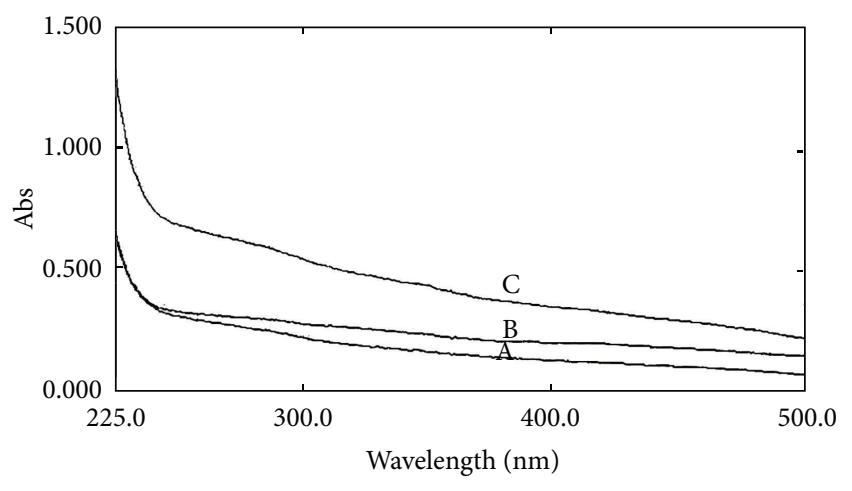

FIGURE 3: The absorption spectra of the samples A, B, and C heated at $1000^{\circ} \mathrm{C}$.

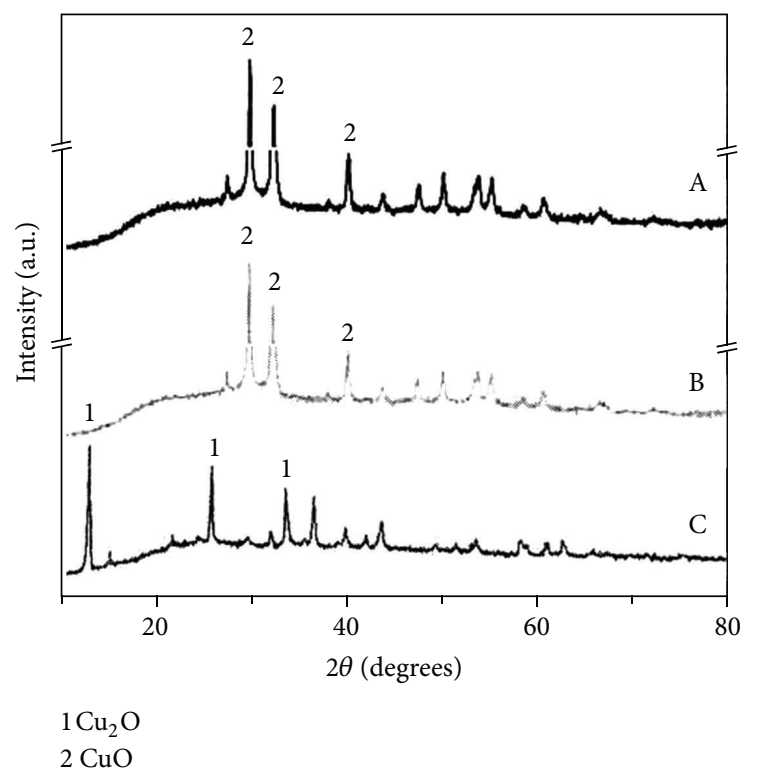

Figure 4: X-ray patterns of $\mathrm{CuO} / \mathrm{SiO}_{2}$ sample concentrated at $\mathrm{A}, \mathrm{B}$, and $\mathrm{C}$ samples.

Figure 3 shows the absorption spectra of the samples A, B, and $\mathrm{C}$ heat-treated at $1000^{\circ} \mathrm{C}$. The powdered samples showed similar absorption spectra to those of $\mathrm{Cu}^{+}$ions. The broad absorption around $780 \mathrm{~nm}$ was completely disappeared from all the samples. Therefore, it seems that, at $1000^{\circ} \mathrm{C}$, the $\mathrm{Cu}^{2+}$ ions might be converted into $\mathrm{Cu}^{+}$ions or $\mathrm{Cu}_{2} \mathrm{O}$. Thus, the reaction of copper metal and oxygen initially yields copper oxide, which is then converted into $\mathrm{Cu}_{2} \mathrm{O}$ during the longer reaction times or at higher concentrations and temperatures $[17,18]$.

Figure 4 presents the X-ray pattern of the $\mathrm{CuO} @ \mathrm{SiO}_{2}$ sample sets annealed at A, B, and C. For the sample annealed at $\mathrm{C}$ label, the pattern corresponding to the copper nitrate is presented to be $\mathrm{Cu}_{2} \mathrm{O}$ of $\mathrm{Cu}^{1+}$ form. Although the amount of the added copper nitrate is below the limit of solubility and all precautions were taken to dissolve it, two states could occur during the thermal treatment of the gel, which explain the later fact that the precipitation of the compounds or separated ions leads to formation of the compounds during the annealing. For the samples concentrated at A and B, it demonstrated the X-ray pattern corresponding to the copper oxide phase in tenorite structure. According to the results, it was shown that there is no evidence of the presence of $\mathrm{Cu}_{2} \mathrm{O}$ species in these samples, but for the sample of $\mathrm{C} \mathrm{X-}$ ray diffraction patterns are not clear at this concentration. In the authors, view, in high concentration $\mathrm{CuO}$ decomposition occurred is and converted to $\mathrm{Cu}_{2} \mathrm{O}$.

The nanostructural characterization of the xerogel was studied by TEM. Powder samples with 10, 20, and $30 \mathrm{wt} \%$ copper oxide, after ambient drying and thermal treatment at $400^{\circ} \mathrm{C}$ in air for $1 \mathrm{~h}$, were objected to TEM using bright field, and the resulted images are shown in Figure 5. No crystalline species were detected without thermal treatment, and the bright field image shows a typical amorphous xerogel. Figure 5(a) exhibits A sample with $10 \mathrm{wt} \%$ in silica matrix that is a network of pores with different average sizes about $50 \mathrm{~nm}$. Also, Figure 5(b) presents the copper ions with $20 \mathrm{wt} \%$ doped into the pores of silica matrix after annealing at $400^{\circ} \mathrm{C}$.

In this figure, the different particles with average size of about $75 \mathrm{~nm}$ that doped and completed the pores of silica matrix can be seen. Figure 5(c) presents TEM micrograph of sample $C$ with $30 \mathrm{wt} \%$ that has average size about $150 \mathrm{~nm}$. It was shown that with increasing concentration particle size increased, but a deformation in micrographs was appeared. With increasing of concentration, numbers of copper ions raises in volume unit and structure move to formation of nanoclusters from $\mathrm{Cu}-\mathrm{O}-\mathrm{Cu}$ that is connected to silica matrix directly. The XRD confirms formation of $\mathrm{Cu}^{1+}$ in sample $\mathrm{C}$ that is unuseful for optical properties. Sample A is the most important sample with the highest transmittance that shows low amount of water and high purity.

The effects of the concentration on the textural properties of the sol-gel samples were presented in Table 1 . The obtained data have shown that the treatment at $400^{\circ} \mathrm{C}$ of A sample produced the largest surface area, pore size radius with the lowest density. These results indicate the loss of volatile compounds from the porous structure. Once the volatile compounds were eliminated from the network, an increase occurs in the porosity, and the gas pores interact [19-21]. Despite this weight loss, a little shrinkage was observed for the material treated at $400^{\circ} \mathrm{C}$, resulting in density decrease. It is interesting for the sample treated at $400^{\circ} \mathrm{C}$ of $\mathrm{B}$ sample, which the surface area reduces by $41.9 \%$ (from 420 to $244 \mathrm{~m}^{2} \cdot \mathrm{g}^{-1}$ ), whereas the pore volume shows a much more pronounced decrease of $68.4 \%$ (from 680 to $214.5 \mathrm{~cm}^{3} \cdot \mathrm{g}^{-1}$ ).

For the sample of $\mathrm{C}$ treated at $400^{\circ} \mathrm{C}$, the surface area decreases by about $53.7 \%$, whereas the pore volume shows $54.3 \%$ reduction. In the authors' view, it was related to the size and shape of micro-, meso-, and macropores, which modify the samples treated at $400^{\circ} \mathrm{C}$. For another sample, the surface area and porosity strongly decrease due to densification process. The results have presented a significant contribution to micropores in the material treated at $400^{\circ} \mathrm{C}$. Comparison of surface area, porosity, density, and pore volumes for these samples and obtained results show that A sample is the best material for catalytic activity [22]. 


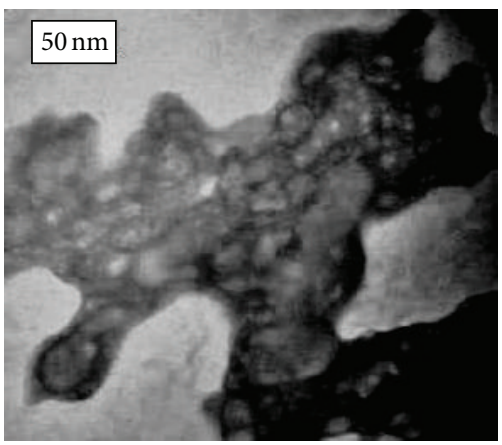

(a)

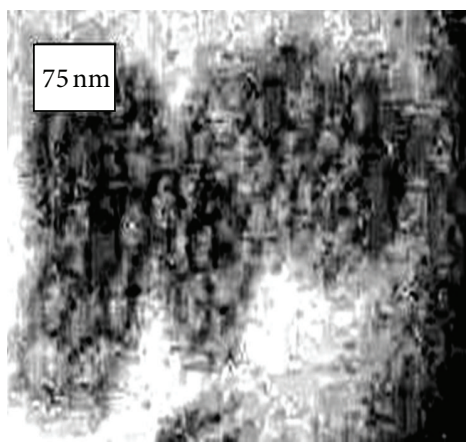

(b)

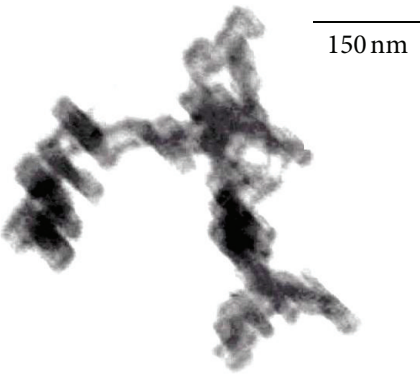

(c)

FIgURE 5: TEM micrograph of (a) sample A (10 wt\%), (b) sample B (20 wt\%), and (c) sample C (30 wt\%).

TABLE 1: Textural properties of A, B, and C samples.

\begin{tabular}{lcccc}
\hline Sample & $\begin{array}{c}\text { Surface area } \\
\left(\mathrm{m}^{2} \mathrm{~g}^{-1}\right)\end{array}$ & $\begin{array}{c}\text { Pore radius } \\
(\AA)\end{array}$ & $\begin{array}{c}\rho_{\text {pic }} \\
\mathrm{g} / \mathrm{cm}^{3}\end{array}$ & $\begin{array}{c}V_{p} \\
\mathrm{~cm}^{3} / \mathrm{g}\end{array}$ \\
\hline A & 420.0 & 21.0 & 0.72 & 680.0 \\
B & 244.0 & 16.0 & 0.78 & 214.5 \\
$\mathrm{C}$ & 112.8 & 8.0 & 0.86 & 98.0 \\
\hline
\end{tabular}

\section{Conclusion}

The broad absorption band of $\mathrm{Cu}^{2+}$ ions in around $780 \mathrm{~nm}$ was related to the legend field splitting of $d$ levels. The transmittance spectra of high temperature treated copper ions doped into silica matrices indicate that the broad bond with filtering effect. Uv-vis spectroscopy presents the sample of A is the most important sample with the highest transmittance that shows low amounts of water and high purity. XRD patterns presents in $\mathrm{A}$ and $\mathrm{B}$ samples, there are copper ions to $\mathrm{Cu}^{2+}$ to tenorite structure, but in $\mathrm{C}$ sample, there are copper ions to $\mathrm{Cu}^{1+}$ form, mainly. Also, the TEM micrographs confirmed the formation of colloidal particles of about 50, 75, and $150 \mathrm{~nm}$ for $\mathrm{A}, \mathrm{B}$, and $\mathrm{C}$ samples, respectively. Also, surface area, porosity, density, and pore volumes compared for these samples and obtained results show that A sample is the best material for catalytic activity. A sample shows the highest surface area and results in the best catalytic activity. The lower concentrations are not suitable for catalytic activity, because the copper oxide quantities are very low. But in case of B and C samples, these are not good for catalytic activity, because copper oxide particles are coagulated together, stay in pores, and do not come to surface for reaction with other molecules to present catalytic activity. According to the results, the exact compositions of nanocomposites depend on the annealing temperatures, the choice of appropriate copper source, and suitable concentration of copper ions in the silica matrices.

\section{References}

[1] L. L. Hench and J. K. West, "The Sol-Gel process," Chemical Reviews, vol. 90, no. 1, pp. 33-72, 1990.

[2] L. C. Klein, "Sol-gel optical materials," Annual Review of Materials Science, vol. 23, no. 1, pp. 437-452, 1993.
[3] D. R. Rolison and B. Dunn, "Electrically conductive oxide aerogels: new materials in electrochemistry," Journal of Materials Chemistry, vol. 11, no. 4, pp. 963-980, 2001.

[4] I. Tseng, W. Chang, and C. S. Wu, "Photoreduction of $\mathrm{CO}_{2}$ using sol-gel derived titania and titania-supported copper catalysts," Applied Catalysis B, vol. 37, no. 1, pp. 37-48, 2002.

[5] M. A. Karakassides, A. Bourlinos, D. Petridis, L. CocheGuerènte, and P. Labbè, "Synthesis and characterization of copper containing mesoporous silicas," Journal of Materials Chemistry, vol. 10, no. 2, pp. 403-408, 2000.

[6] J. L. Mohanan and S. L. Brock, "Influence of synthetic and processing parameters on the surface area, speciation, and particle formation in copper oxide/silica aerogel composites," Chemistry of Materials, vol. 15, no. 13, pp. 2567-2576, 2003.

[7] C. M. Parler, J. A. Ritter, and M. D. Amiridis, "Infrared spectroscopic study of sol-gel derived mixed-metal oxides," Journal of Non-Crystalline Solids, vol. 279, no. 2-3, pp. 119-125, 2001.

[8] S. Ikoma, K. Kawakita, and H. Yokoi, "Characterization of polyamine copper(II) complex-doped alumina gels prepared by the sol-gel technique," Journal of Non-Crystalline Solids, vol. 122, no. 2, pp. 183-192, 1990.

[9] O. De Sanctis, L. Gómez, N. Pellegri, C. Parodi, A. Marajofsky, and A. Durán, "Protective glass coatings on metallic substrates," Journal of Non-Crystalline Solids, vol. 121, no. 1-3, pp. 338-343, 1990.

[10] J. F. Perez-Robles and J. Gonzales-Hernandez, "Characterization of sol-gel glasses with different copper concentrations treated under oxidizing and reducing conditions," Journal of Physics and Chemistry of Solids, vol. 60, no. 10, pp. 1729-1736, 1999.

[11] E. M. B. De Sousa, A. O. Porto, P. J. Schilling, M. C. M. Alves, and N. D. S. Mohallem, "Study of the structural evolution of copperdoped porous silica gels," Journal of Physics and Chemistry of Solids, vol. 61, no. 6, pp. 853-861, 2000.

[12] J. R. Martínez, S. Palomares-Sánchez, G. Ortega-Zarzosa, F. Ruiz, and Y. Chumakov, "Rietveld refinement of amorphous $\mathrm{SiO}_{2}$ prepared via sol-gel method," Materials Letters, vol. 60, no. 29-30, pp. 3526-3529, 2006.

[13] S. H. Tohidi, A. J. Novinrooz, and M. Derhambakhsh, "Preparation and study of molecular structure of copper ions doped in a silica xerogel matrix," International Journal of Engineering, Transactions B, vol. 19, no. 1, pp. 53-60, 2006.

[14] J. R. Martínez, F. Ruiz, Y. V. Vorobiev, F. Pérez-Robles, and J. González-Hernández, "Infrared spectroscopy analysis of the 
local atomic structure in silica prepared by sol-gel," Journal of Chemical Physics, vol. 109, no. 17, pp. 7511-7514, 1998.

[15] Z. Wang, Q. Liu, J. Yu, T. Wu, and G. Wang, "Surface structure and catalytic behavior of silica-supported copper catalysts prepared by impregnation and sol-gel methods," Applied Catalysis A, vol. 239, no. 1-2, pp. 87-94, 2003.

[16] S. H. Tohidi, G. L. Grigoryan, and A. J. Novinrooz, "The effect of thermal treatment on the structural properties of coppercontaining sol-gel silica nanocomposites," International Journal of Materials Research, vol. 102, no. 10, pp. 1247-1251, 2011.

[17] F. Ruiz, J. R. Martinez, and J. Gonzalez-Hernandez, "Formation of silicate structures in Cu-containing silica xerogels," Journal of Materials Research, vol. 15, no. 12, pp. 2875-2880, 2000.

[18] R. R. Conry and D. K. Karlin, Encyclopedia of Inorganic Chemistry, vol. 2, John Wiley \& Sons, Oxford, UK, 1994.

[19] J. R. Martínez, F. Ruiz, J. A. de la Cruz-Mendoza et al., "Structural evolution of silica-gel in the late stages of the gelation process," Revista Mexicana de Física, vol. 44, no. 6, pp. 575-579, 1998.

[20] J. A. Calderon-Guillen, L. M. Aviles-Arellano, J. F. Perez-Robles, and J. F. Gonzalez-Hernandez, "Dense silica-based coatings prepared from colloidal silica," Surface and Coatings Technology, vol. 190, no. 1, pp. 110-114, 2005.

[21] S. B. Ogale, P. G. Bilurkar, N. Mate, S. M. Kanetkar, N. Parikh, and B. Patnaik, "Deposition of copper oxide thin films on different substrates by pulsed excimer laser ablation," Journal of Applied Physics, vol. 72, no. 8, pp. 3765-3769, 1992.

[22] S. H. Tohidi, "Comparision of synthesis and characterization of copper species nanostructures on the silica matrix," International Journal of Nanoscience and Nanotechnology, vol. 7, no. 1, p. 7, 2011. 

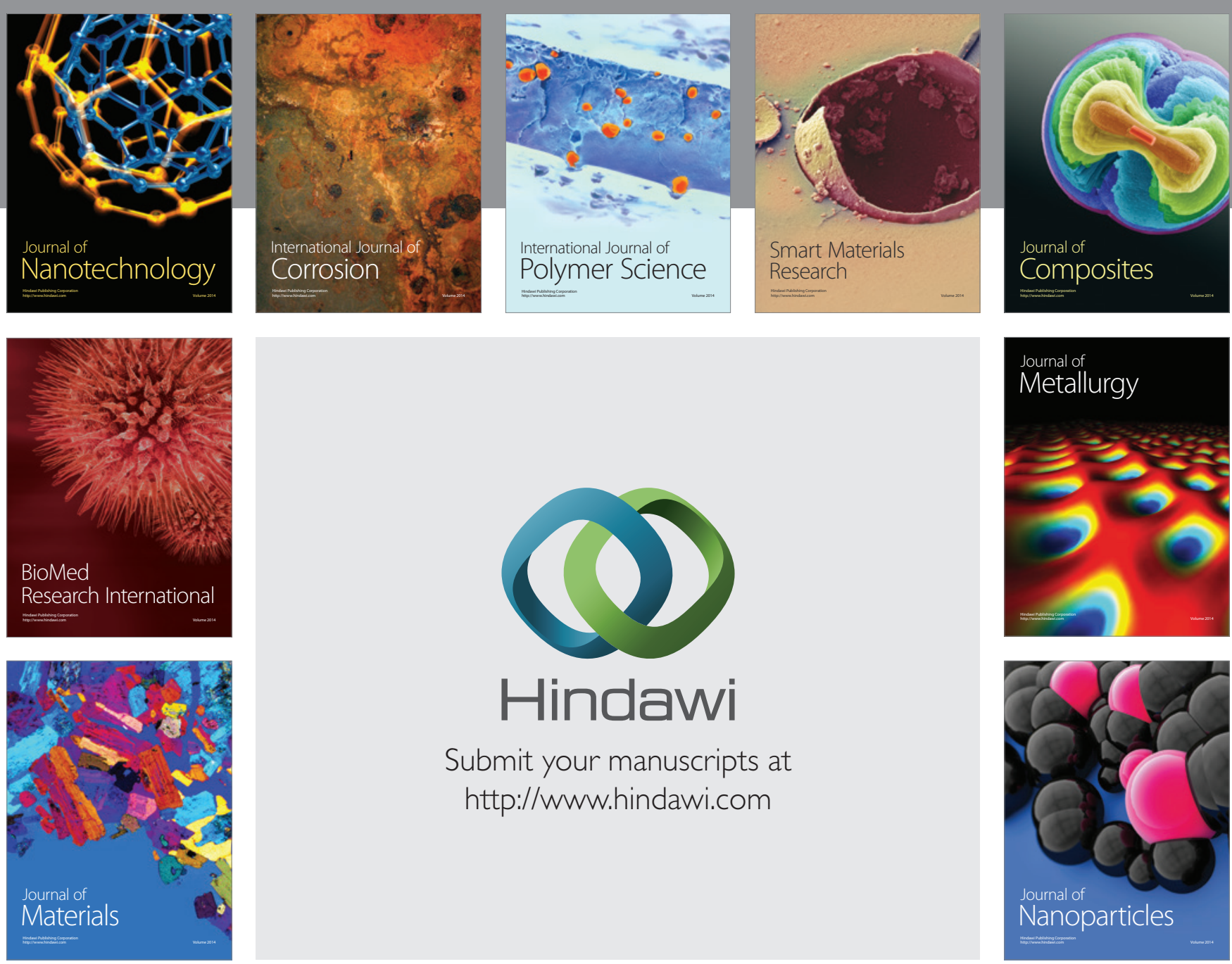

Submit your manuscripts at http://www.hindawi.com
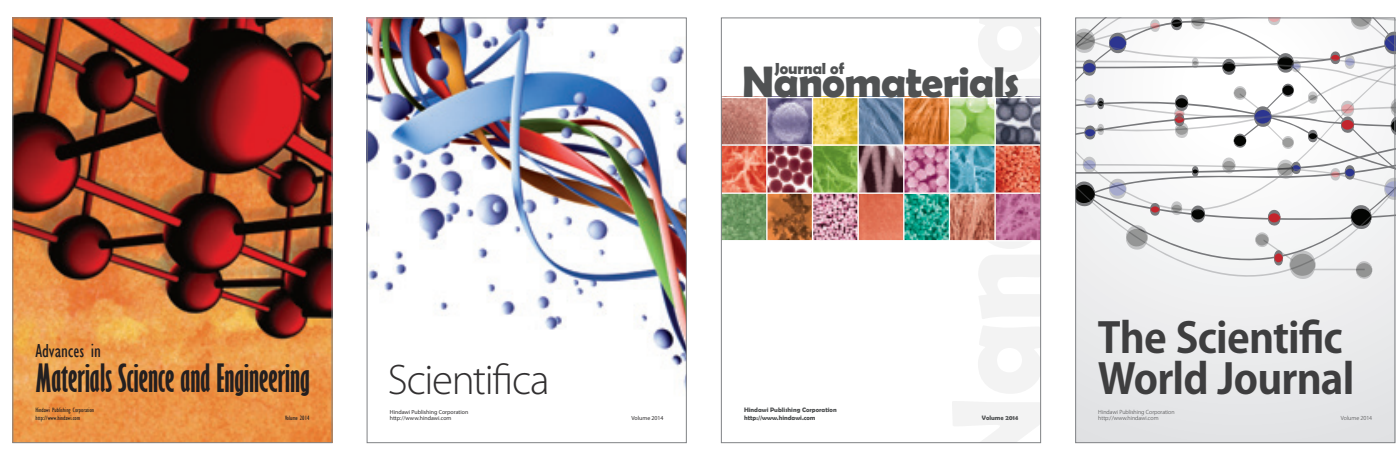

\section{The Scientific World Journal}
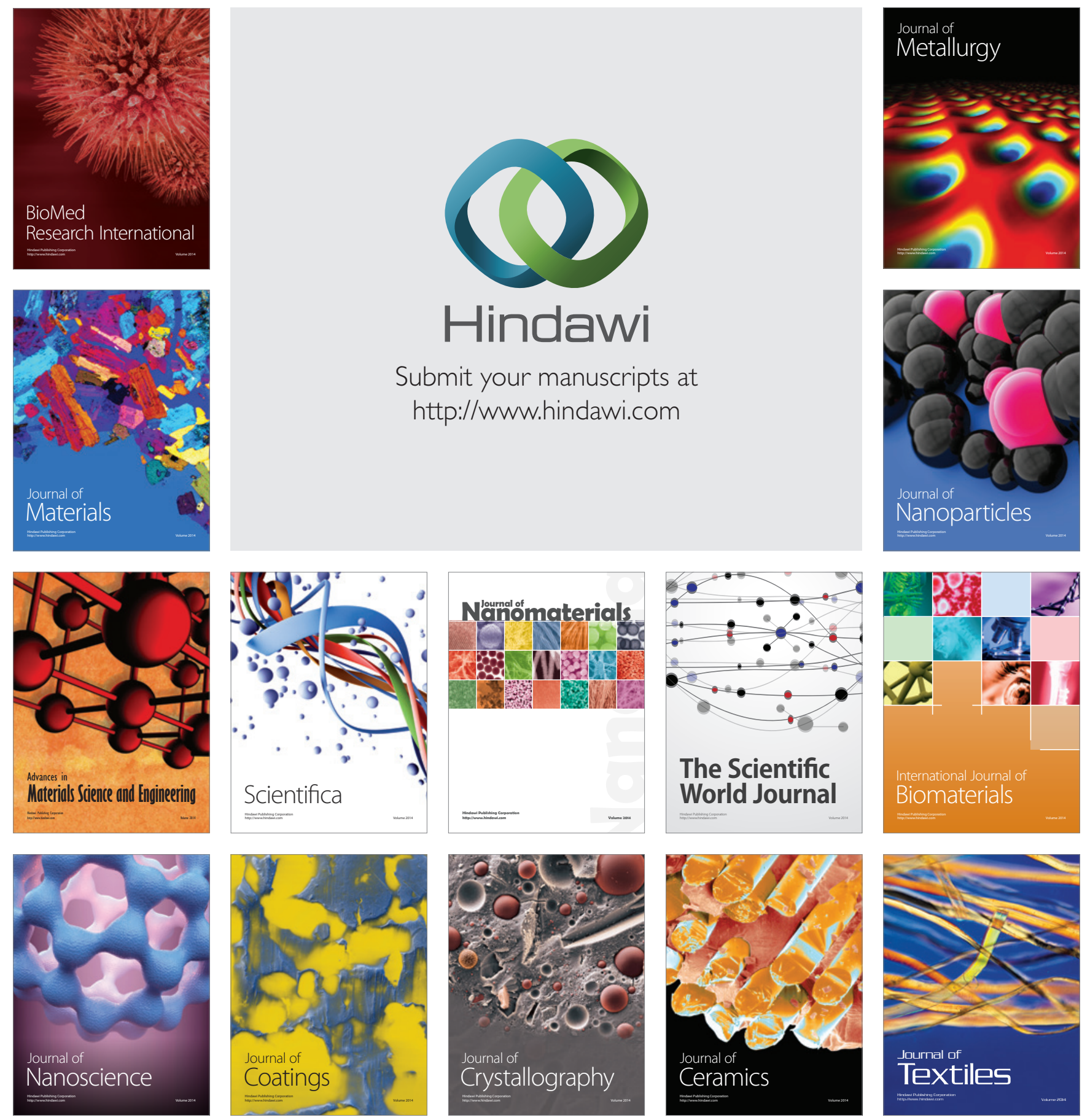